\title{
Synthetic cannabis: what doctors need to know
}

\begin{abstract}
The use of synthetic cannabinoids (SC) is a serious and ongoing public health problem in the United States. It appeals to a younger population as well as people with mental illness. It is inexpensive in comparison to natural marijuana and readily available in the community. Here we explore the psychiatric and medical sequela of SC as well as the ongoing public health concern of this harmful substance and the role for psychiatrists.
\end{abstract}

\author{
Volume 2 Issue 2 - 2016 \\ Panagiota Korenis, Sabina Fink, Ronak Patel,
Raminder Cheema, Houssam Raai, Luisa
Gonzalez
Department of Psychiatry, Bronx Lebanon Hospital Center, USA
}

Correspondence: Panagiota Korenis, Program Director, Residency Training, Department of Psychiatry, Bronx Lebanon Hospital Center, USA, Email korenismd@gmail.com

Received:September 25, 2016 | Published: November 02, 2016

\section{Introduction}

Synthetic cannabis (SC) use has become a widespread epidemic in various parts of the United States. Illicit use of this devastating drug is manifested in both psychiatric and medical sequelae, resulting in various clinical presentations and posing a major challenge to clinicians regarding the identification of potential symptoms and subsequent treatment. SC is sold illegally throughout the United States and particularly in New York City, where its colourful packaging, availability and inexpensive cost makes it appealing to users of all ages. It is particularly popular amongst adolescents and young adults. From its naissance in the 1980 s, SC was championed for its analgesic properties however was found to be considerably more potent and detrimental than the psychoactive ingredient in natural marijuana, tetrahydrocannabinol (THC). By 2009, SC found its way to North America. ${ }^{1}$ Consequently, multiple hospitalizations and even death have occurred amongst SC users.

\section{Mechanism of action and psychogenic properties of synthetic cannabinoids}

Synthetic cannabis is a designer drug in which herbs or other leafy materials are sprayed with lab-synthesized liquid chemicals to mimic the effect of tetrahydrocannabinol (THC), the psychoactive ingredient in the naturally grown marijuana plant (cannabis sativa). It acts as an agonist at cannabinoid receptors which are located in

Table I Differences between synthetic cannabinoids and cannabis various brain regions impacting mood, appetite, pain and immunity (Table 1). Currently, there are over 700 researched cannabinoid (CB) receptors identified with $\mathrm{CB} 1$ and $\mathrm{CB} 2$ playing the most significant role resulting in psychoactive effects. $\mathrm{CB} 1$ receptors are mainly located in the hypothalamus, cerebellum and hippocampus. It has an impact on mood, appetite, pain and memory. In addition, SC also has some effect on CB2 which can affect the immune system. ${ }^{2}$ While cannabis is a naturally occurring agent with receptors in the brain, the effects of SC are up to 800 times more potent than the active ingredient in cannabis. The $\mathrm{CB} 1$ receptor is predominantly expressed presynaptically, modulating the release of neurotransmitters including GABA, dopamine, noradrenaline, glutamate and serotonin. While $\mathrm{SC}$ use has been known to cause hallucinations and psychosis, the manner in which SC affects the release of these neurotransmitters is not fully understood and may entail abnormal dopaminergic and serotonergic transmission and N-Nitrosodimethylamine (NMDA) receptor blockade. This is similar to the drugs phencyclidine and Ketamine. Although both THC and SC undergo Phase I metabolism by cytochrome $\mathrm{P} 450$, JWH-018 has been shown to have at least nine metabolites whose biological activity is currently undetermined, while THC has one known major psychoactive metabolite. ${ }^{3}$ While natural cannabinoids have been shown to exhibit anticonvulsive activity, seizures caused by SC use are possibly due to the antagonism of other inhibitory networks such as GABA channels or the activation of excitatory networks such as glutamate receptors, $\mathrm{Na}^{+}$and $\mathrm{Ca}^{2+}$ channels. ${ }^{4}$

\begin{tabular}{|c|c|c|}
\hline & Synthetic Cannabinoids (K2) & Cannabis \\
\hline Mechanism of Action & $\begin{array}{l}\text { Acts as a full agonist on CBI receptors (Psychotomimetic action; } 800 \\
\text { time's higher receptor affinity Vs Cannabis). } \\
\text { Also acts on CB2, Dopamine, NMDA/Glutamate, GABA, Serotonin, } \alpha_{1} \text {, } \\
\beta_{1} \text { and } \beta_{2} \text { receptors. }\end{array}$ & Partial agonist on $\mathrm{CBI}$ receptors. \\
\hline Adverse Effects & $\begin{array}{l}\text { Psychiatric: Acute agitation, anxiety, depression, hallucinations, } \\
\text { perceptual disturbances, suicidal ideations, homicidal ideations, panic } \\
\text { attacks, paranoia, and psychosis. } \\
\text { Medical: Nausea, vomiting, tachycardia, drowsiness, dizziness, } \\
\text { hypertension, myocardial infarction, seizures, convulsions, kidney failure, } \\
\text { rhabdomyolysis and death. }\end{array}$ & $\begin{array}{l}\text { Rare reporting of nausea, } \\
\text { increased weakness, fatigue, } \\
\text { behavioral, mood changes, suicidal ideation, } \\
\text { hallucinations, dizziness, } \\
\text { vasovagal symptoms and } \\
\text { feelings of intoxication. }\end{array}$ \\
\hline Lethal Human Dose & Unknown & IV dronabinol 30 mg/kg \\
\hline
\end{tabular}


Table Continued...

\begin{tabular}{|c|c|c|}
\hline & Synthetic Cannabinoids (K2) & Cannabis \\
\hline $\begin{array}{l}\text { Urine Toxicology } \\
\text { Screen }\end{array}$ & $\begin{array}{l}\mathrm{K} 2 \text { is detected by GCMS \& its molecular structure can be altered to } \\
\text { avoid detection. }\end{array}$ & $\begin{array}{l}\text { Detected in standardized } \\
\text { urine drug screen. }\end{array}$ \\
\hline Metabolism & $\begin{array}{l}\text { Phase I metabolism of } \mathrm{K} 2 \text { results in at least nine monohydroxylated } \\
\text { metabolites. (Mechanism unknown). }\end{array}$ & Has one metabolite. \\
\hline
\end{tabular}

Effects of SC use can include acute agitation, paranoia, depression, hallucinations and other perceptual disturbances and a number of medical manifestations including nausea, vomiting, tachycardia, seizures, kidney failure and death. ${ }^{5}$ Cardiovascular and CNS toxicity are reported to be related to the long term abuse-related effects of dependence and withdrawal. ${ }^{6}$ A case report noted how SC use initially caused a pressor-like effect, followed by vasodilation, subsequent reflex tachycardia and ischemia. ${ }^{6}$ The cardiovascular symptoms, as well as drug-induced anxiety, agitation and panic attacks associated with SC use could therefore be caused by activation of $\alpha_{1}, \beta_{1}$ and $\beta_{2}$ adrenoreceptors. $^{7}$ Activation of glutamate receptors and GABA channel blockade may also be responsible for anxiety due to SC use. ${ }^{8}$ Agitation and violent behavior, suicidal and homicidal ideations in addition to self-injurious behaviors have been reported in case studies. ${ }^{9}$ The implications of acute SC use on human health remains poorly understood and less is known about the long term effects of these drugs. Currently, there are no standard treatment protocols for complications arising from SC use as only supportive and symptomatic treatment is provided. After drug cessation, mental health and addiction issues must be addressed and the treatment team must be cognizant that psychotic or suicidal ideations may persist after treatment, thus clinicians should incorporate SC use into intake and assessment.

\section{Government initiative and legal aspect}

There is an increasingly expanding array of synthetic drugs available. To put things into perspective, in 2009 only two synthetic cannabinoids were identified but by 2012 more than 51 have been reported. This increasingly dangerous epidemic motivated the white house to issue an official warning on the white house official web page stating that the use of synthetic cannabinoids is becoming alarmingly high. Attached to it a result of a survey conducted in 2012 which showed that one in nine $12^{\text {th }}$ graders in the United States reported using SC. ${ }^{10}$

\section{The synthetic drug abuse prevention act (20 I 2)}

It was signed into law by President Obama in 2012, and permanently placed 26 types of synthetic cannabinoids into Schedule I of the Controlled Substances Act (CSA). ${ }^{11}$ The CSA is the statute prescribing federal U.S. drug policy and regulates the possession, use and distribution of certain substances. All of the drugs listed as Schedule I have been deemed to have a high potential for abuse, not accepted by medical specialists in the US as treatment and the drug is unsafe for human consumption.

\section{Fighting $\mathrm{K} 2$ in new york city}

According to the official website of the City of New York; there have been more than 6,000 synthetic cannabinoid-related ER visits in NYC area hospitals. The corner of $125^{\text {th }}$ Street and Lexington Avenue was identified as being at the center of the SC problem in New York. ${ }^{12}$
On October $20^{\text {th }}, 2015$ Mayor de Blasio signed into law three bills to criminalize sale and production of SC. These new bills are part of a multi-agency enforcement, education and prevention strategy against SC. The new laws provide the City with additional tools and penalties to reduce the sale and manufacture of SC including making it a misdemeanour to sell SC and to revoke a cigarette dealer's licensure if they are found to be selling it. ${ }^{13}$

On November $16^{\text {th }}, 2015$, a summit titled "K2 in NYC: Promoting Public Health and Safety," was co-hosted by the NYC Department of Consumer Affairs, the NYPD, and Department of Health and Mental Hygiene, at Brooklyn Law School to discuss the best ways to address the SC synthetic drug crisis in NYC. The summit provided judges, first responders, law enforcement and public health professionals with resources to effectively implement the new criminal provision barring the sale of SC, connect users to treatment in the short-term, and ensure that users are connected to stabilizing services in the long-term. ${ }^{13}$

Multiple steps have been taken to reduce the supply of SC in the city; during September 2015 the NYPD and DEA seized $\$ 17.5$ million worth of SC product and ingredients-including at least 200 $\mathrm{kg}$ of synthetic compounds used to make SC, and 150,000 packets of finished SC. More than 80 stores throughout New York City were inspected as part of the enforcement action. In the following 3 weeks, there were $22 \%$ fewer SC-related ER visits compared with the 3 weeks prior to the seizures. In addition the Department of Consumer Affairs (DCA) has been issuing labeling violations for inadequate and misleading labelling of synthetic cannabinoids. ${ }^{11}$

\section{Can legalizing marijuana help?}

An article prepared by Professor Jon Gettman from Shenandoah University titled, "Arrests in Colorado after the Passage of Amendment 64" published on March 25 , 2015: reports a sharp decline in SC arrests since retail stores selling marijuana opened in 2014 . The article contained data from the judicial county court records, and showed that arrests for SC in 2014 have declined by 50\% from the prior year. ${ }^{14}$

Given the health impacts of marijuana are more predictable and understood than those related to synthetic marijuana, advocates see this as yet another potential benefit of legalization.

\section{Role of psychiatrists}

With growing legislation legalizing marijuana use, psychiatrists more than ever need to understand the widespread usage and potential clinical implications of such substances. As mental health workers we carry the responsibility of educating mental health and substance abuse patients on risks and consequences of synthetic cannabis use, educating physicians and healthcare workers in other specialties on synthetic cannabis effects and clinical presentations. In addition to reaching out to communities, schools, shelters and group homes to raise awareness about synthetic cannabis health risks. Our team has been educating our community and our colleagues about the importance of recognizing patients who are intoxicated with SC. 


\section{Acknowledgements}

None.

\section{Conflict of interest}

The author declares no conflict of interest.

\section{References}

1. Welcome to Spice Addiction Support.

2. Volker A, Paul ID, David MW. Novel Psychoactive Substances, Classification, Pharmacology and Toxicology. Synthetic Cannabinoid Receptor Agonist. 2013;317-343.

3. McCoy T. How this chemist unwittingly helped spawn the synthetic drug industry. Washington USA, 2015.

4. Schlicker E, Kathmann M. Modulation of transmitter release via presynaptic cannabinoid receptors. Trends Pharmacol Sci. 2001;22(11):565-572.

5. Huffman JW, Zengin G, Wu MJ, et al. Structure-activity relationships for 1-alkyl-3-(1-naphthoyl)indoles at the cannabinoid $\mathrm{CB}(1)$ and $\mathrm{CB}(2)$ receptors: steric and electronic effects of naphthoyl substituents. New highly selective CB (2) receptor agonists. Bioorg Med Chem. 2005;13(1):89-112.
6. Brents LK, Reichard EE, Zimmerman SM, et al. Phase I Hydroxylated Metabolites of the K2 Synthetic Cannabinoid JWH-018 Retain In Vitro and In Vivo Cannabinoid 1 Receptor Affinity and Activity. PLoS One. 2011;6(7):e21917.

7. Tai S, Fantegrossi WE. Synthetic Cannabinoids: Pharmacology, Behavioural Effects, and Abuse Potential. Curr Addict Rep. 2014;1(2):129-136.

8. Ibrahim S, Al-Saffar F, Wannenburg T. A Unique Case of Cardiac Arrest following K2 Abuse. Case Reports in Cardiology. 2014;2014(2014):1-3.

9. Thomas S, Bliss S, Malik M. Suicidal ideation and self-harm following K2 use. J Okla State Med Assoc. 2012;105(11):430-433.

10. Fink S, Patel R, Cheema R, et al. Clinical characteristics of synthetic cannabinoids users on the inpatient psychiatric service. 2016.

11. Walsh, Kathleen. Synthetic Cannabinoids: A Public Health Concern. Atlanta, Georgia, 2016.

12. Synthetic Drugs (a.k.a. K2, Spice, Bath Salts, etc.). 2012.

13. Mayor de Blasio Signs K2 Legislation into Law Criminalize Sale and Production. 2015.

14. Gettman JB. Arijuana Arrests in Colorado After the Passage of Amendment 64. Drug Policy Alliance. 2015;1-17. 